\title{
RASISME DAN PERSPEKTIF ANAK DALAM NOVEL WHEN HITLER STOLE PINK RABBIT KARYA JUDITH KERR
}

\author{
Pangesti Rokhi Dewi \\ Fakultas Ilmu Budaya Unpad \\ pangesti.rokhi@gmail.com \\ Tisna Prabasmoro \\ Fakultas Ilmu Budaya Unpad \\ tisna.prabasmoro@unpad.ac.id \\ Sri Rijati Wardiani \\ Fakultas Ilmu Budaya Unpad \\ sri.rijati@unpad.ac.id
}

\begin{abstract}
Abstrak
Penelitian ini bertujuan untuk menganalisis perspektif tokoh anak Yahudi, yakni Anna dan Max terhadap rasisme selama Hitler memimpin Jerman pada tahun 1933 yang tergambar dalam novel anak When Hitler Stole Pink Rabbit karya Judith Kerr. Dalam penelitian ini digunakan teori naratologi dari Genette (1980), dan konsep rasisme yang dikemukakan oleh Fredrickson (2015) dan Better (2008). Penelitian ini menggunakan metode deskriptif kualitatif untuk menganalisis novel. Hasil penelitian ini adalah terdapat dua jenis rasisme pada novel tersebut, yakni rasisme institusi yang ditunjukkan oleh Nazi dan individu yang ditunjukkan oleh anak dan orang tuanya yang pro terhadap Nazi, serta teman-teman sekolah Max. Penelitian ini pun menunjukkan fokalisasi Anna dan Max baik yang dituturkan oleh mereka sendiri maupun narator tentang rasisme sebagai bentuk represi terhadap fisik dan psikis mereka. Mereka dapat meresistensi semua rasisme yang mereka alami dengan menjadi orang Yahudi yang lebih baik untuk mematahkan prasangka yang melekat pada Nazi maupun orang-orang yang membenci mereka.
\end{abstract}

Kata Kunci: rasisme, nazi, perspektif anak, sastra anak, naratologi

\begin{abstract}
This research aims to analyze the Jewish children's perspective, namely Anna and Max, on racism during Hitler's leadership in Germany in 1933 in the children's novel When Hitler Stole Pink Rabbit by Judith Kerr. The theories used in this research are narratology of Genette (1980), and the concept of racism proposed by Fredrickson (2015) and Better (2008). This study used descriptive qualitative method to analyze the novel. The article is to show the two occurrences of racism in the novel; racism shown by Nazis and individuals shown by children and parents who are pro-Nazi, as well as Max's school friends. The article examined Anna and Max's focalizations, both spoken by themselves and by the narrator. The article eventually argues that Anna and Max's perspective about racism is a form of repression towards their physical and psychological aspects. They withstand racial oppression by becoming better Jews to break the prejudices attached to the Nazis or those who associate them.
\end{abstract}

Keywords: racism, nazi, children's perspective, children's literature, narratology 


\section{PENDAHULUAN}

Isu rasisme hingga diskriminasi melekat pada wacana multikulturalisme. Hal tersebut tidak muncul begitu saja, melainkan merupakan manifestasi dari akumulasi peristiwa-peristiwa kelam masa lalu. Peristiwa di masa lalu tersebut pun meninggalkan residu-residu yang layak dikaji kembali karena dapat memutus mata rantai kesalahpahaman atas pendefinisian ras dan etnisitas yang dipahami hingga saat ini sebagaimana pendapat Stuart yang dijelaskan oleh Bhabha, bahwa "For Stuart, the toil of historical understanding and the task of cultural justice were always urgent - and inevitably unfinished." (Bhabha, 2015), yang berarti kerja keras untuk memahami sejarah dan keadilan budaya selalu menjadi tugas yang mendesak dan belum selesai.

Makna modern dari ras yang dipahami saat ini berakar dari bidang zoologi (Blumenbach, 2018: 2). Manusia diklasifikasi ke dalam kategori warna, yakni hitam, cokelat, merah, dan putih. Namun perbedaan biologis tersebut memicu munculnya diferensiasi sosial dan hal tersebut dianggap sebagai hal yang alamiah serta memicu munculnya rasisme atau anggapan bahwa ras tertentu secara inheren lebih unggul atau lebih rendah dari yang lain (Banks, 2020: 4). Rasisme menjadi suatu ideologi yang bersifat menindas dan dogmatis terjadi saat tahun-tahun Perang Dunia meledak (Barkan, 1992: 15), bahkan hingga saat ini rasisme pun masih dilanggengkan baik secara sistematis oleh negara maupun individu (Elias \& Feagin, 2016: 281). Salah satu peristiwa kelam yang berwujud rasisme sekaligus menarik perhatian dunia adalah masa perang dunia kedua yang berlangsung pada tahun 1933 (Sontheimer, 2005). Hitler sebagai pemimpin rezim Nazi Jerman sekaligus sebagai salah satu tokoh penting pada perang dunia kedua pada saat itu menggaungkan ujaran dan tindakan rasis kepada ras Yahudi yang ia anggap lebih rendah dari pada ras Arya, sehingga mereka tidak pantas berada di Jerman (Fredrickson \& Camarillo, 2015).

Peristiwa tersebut pun kemudian turut menyumbang tindakan atau ujaran kebencian yang bersifat rasis terhadap ras atau etnis lain yang dianggap inferior hingga saat ini. Hal tersebut membuktikan bahwa istilah 'ras' sesungguhnya tidak saja menjelaskan tentang fitur biologis, budaya, dan geografis yang melekat pada diri manusia seperti yang dikemukakan oleh Wright sebagaimana yang dijelaskan oleh López dan Delgado (1999: 14), tetapi di balik penggolongan ras tersebut ada kompleksitas yang ditempelkan pada berbagai wacana. Wacana tersebut pun dibangun oleh pihak yang menganggap dirinya "mayoritas", "berkuasa", atau "menang", sehingga pihak oposisi akan dianggap sebagai "liyan" kemudian dikonstruksi menjadi pihak yang "patut" atau "normal" jika mendapat ujaran dan tindakan rasis. Peristiwa yang menggambarkan rasisme tersebut pun lalu didokumentasikan dalam berbagai bentuk, yakni buku sejarah, koran, berita, film, bahkan karya sastra. Manuaba (2019: 178) menyatakan bahwa sastra dapat menjadi sumber sejarah karena pada dasarnya pengarang menulis apa yang ia alami atau pikirkan yang bersumber dari lingkungan sosialnya, sehingga tidak dipungkiri bahwa sejarah yang dituliskan di dalam karya sastra memang bersifat subjektif, namun dapat menjadi salah satu yang kredibel. Beberapa karya sastra yang menggambarkan wacana multikulturalisme berupa potret rasisme dengan latar perang dunia kedua ini di antaranya adalah novel Charlotte karya David Foenkinos, novel Hannas Koffer karya Levine, novel The Book Thief karya Markus Zusak, novel 
When Hitler Stole Pink Rabbit karya Judith Kerr, dan lain sebagainya. Di antara novelnovel tersebut, novel When Hilter Stole Pink Rabbit merupakan karya sastra anak dan merupakan karya semi-autobiografi, yakni sebuah karya fiksi yang sangat dipengaruhi oleh peristiwa-peristiwa dalam kehidupan seorang pengarang (Collins, 2018).

Judith Kerr sebagai pengarang sekaligus penyintas genosida Yahudi pada tahun 1933 bercerita tentang kisah keluarga Yahudi yang melarikan diri dari Berlin, Jerman pada detik-detik awal Hitler berkuasa, hingga akhirnya menjadi pengungsi dan imigran di negara Swiss, Perancis, dan Inggris. Kerr memilih bercerita dari sudut pandang Anna pada tahun 1933 yang pada saat itu berusia sembilan tahun. Dengan karyanya tersebut, Kerr mendapatkan penghargaan pada tahun 2012 sebagai kategori The Most Excellent Order of British Empire untuk karya sastra anak dan pendidikan Holocaust (Akmen, 2019).

Istilah 'semi-autobiografi' yang melekat pada novel tersebut mengartikulasikan bahwa Judith Kerr sebagai pengarang dari karya sastra tersebut pun mengalami diskriminasi ras seperti yang tergambar pada novel yang ditunjukkan melalui tokoh utama, Anna. Kerr menempatkan diri sebagai liyan sekaligus pengungsi yang hijrah dari Jerman ke negara-negara tetangga hingga akhirnya ke Inggris sebagai imigran untuk mendapatkan harapan kehidupan yang lebih layak serta bebas dari diskriminasi. Hal tersebut merupakan salah satu unsur penting dalam pertimbangan dipilihnya novel When Hitler Stole Pink Rabbit sebagai subjek penelitian. Penelitian ini pun kemudian akan menganalisis bagaimana perspektif tokoh anak tentang rasisme dinarasikan. Pada karya semi-autobiografi isu rasisme akan dinarasikan secara kredibel oleh pengarang yang mengalami rasisme secara langsung, sehingga narasi tentang rasisme yang dihasilkan oleh karya semi autobiografi pun dapat mempermudah proses menganalisis.

Dikemasnya potret rasisme dalam sastra anak menunjukkan bahwa isu rasisme yang merupakan bagian dari sejarah kelam dunia dan cenderung bersifat diskriminatif tidak serta merta didokumentasikan oleh karya-karya sastra dengan segmentasi pembaca dewasa saja, tetapi juga dapat merambah pada sastra anak dan remaja. Hal tersebut pun sesuai dengan apa yang dikatakan oleh Gansel (2010: 12), bahwa "... dass die KJL (Kinder-und Jugendliteratur) eben nicht mehr bevorzugt als Mittel zur moralischen Belehrung funktioniert oder eine Art Erziehungsmittel ist.", yakni sastra anak (seharusnya) tidak hanya berhenti pada titik edukasi dan moralitas, melainkan harus memiliki fungsi lain pula.

Novel When Hitler Stole Pink Rabbit merupakan salah satu karya sastra anak yang penting pada wacana multikulturalisme karena menjadi bagian dari pematah stereotip dan prasangka yang melekat pada kaumnya, orang Yahudi sebagai korban rasisme. Kerr bercerita tentang isu-isu rasisme dan diskriminasi yang terjadi pada rezim Nazi, sekaligus menjadi sejarah yang ditulis dari sudut pandang baru, yakni anak-anak. Meskipun menggambarkan keadaan anak-anak yang menjadi korban rezim Nazi, cerita dalam novel tersebut tetap dikemas ringan dan memiliki unsur keceriaan dan kegembiraan khas anak-anak.

Tidak dapat dipungkiri pula bahwa terdapat beberapa penelitian yang berobjek penelitian berupa karya-karya sastra, dan yang menggunakan sudut pandang sejarah serta menganalisis isu rasisme, khususnya pada kekejaman Nazi dalam teks. Penelitian terdahulu yang telah membahas isu tersebut antara lain 
adalah "Rasisme dalam Novel Hanas Kofer Karya Levine“ oleh Muqil dan Kurniawati (2015). Penelitian ini menggunakan teori Fredickson. Hasil penelitian ini adalah peristiwa yang menggambarkan adanya tindakan rasis dalam novel Hanas Koffer karya Levine ditunjukkan dengan penyiksaan maupun pembunuhan ras Yahudi. Kemudian penelitian yang ditulis oleh Intan (2017) yang berjudul "Novel Charlotte Karya David Foekinos: Sebuah Narasi tentang Diskriminasi, Rasisme, dan Holocaust" menggunakan teori Fredrickson. Hasil penelitian ini adalah dapat dipahami bahwa pengarang berupaya mengingatkan pembaca terhadap hak-hak azasi manusia dan sesungguhnya apa yang dilakukan Nazi pada masa lalu bukanlah sebuah tindakan yang datang dari hati nurani manusia. Penelitian terakhir yang relevan dengan artikel ini adalah "Construcción de la identidad diaspórica en la autobiografía infantil: When Hitler Stole Pink Rabbit (1971), de Judith Kerr" oleh Soledad Pérez. Penelitian ini berfokus pada kajian linguistik untuk mengkonstruksi representasi konstruksi identitas yang menunjukkan traumatis dari Judith Kerr sebagai pengarang.

Ketiga penelitian tersebut memiliki persinggungan dengan artikel ini berupa isu yang sama, yakni rasisme pada masa Nazi berkuasa. Namun masih jarang penelitian yang menggunakan novel anak When Hitler Stole Pink Rabbit karya Judith Kerr sebagai objek penelitian. Penelitian terdahulu pun belum menyentuh ranah perspektif tokoh anak dengan menggunakan konsep focalization dan voice dari Genette (1980) untuk mengidentifikasi bagaimana pandangan tokoh anak sebagai korban rasisme dalam mengalami diskriminasi dari semua elemen-elemen di sekitarnya, baik secara institusi maupun individu. Kata "anak" kemudian menjadi penanda penting pada penelitian ini karena pada umumnya penelitian yang menyandingkan tema rasisme dan karya sastra anak masih jarang dikaji oleh peneliti lainnya, sehingga hasil dari penelitian ini akan menyuguhkan perspektif baru dalam ranah kajian rasisme, yakni dari perspektif tokoh anak. Selain masih jarangnya penggunaan sastra anak dalam pengkajian isu rasisme, sastra anak juga dipilih sebagai objek penelitian karena unsur nuansa dan ketatabahasaan "ke-kanak-an" yang akan menempel pada narasi rasisme, sehingga memberikan fokalisasi anak yang otentik.

Dengan demikian permasalahan yang dibahas dalam artikel ini adalah bagaimana perspektif tokoh anak tentang rasisme dinarasikan dalam novel When Hitler Stole Pink Rabbit karya Judith Kerr. Artikel ini pun akan mengidentifikasi jenis rasisme yang dinarasikan berdasarkan model Better (2008). Berangkat dari permasalahan tersebut, penelitian ini bertujuan untuk mengungkap fokalisasi Anna dan Max sebagai tokoh anak yang ditunjukkan dalam memandang rasisme yang menimpa mereka.

\section{METODE PENELITIAN}

Metode yang digunakan dalam artikel ini adalah deskripsi kualitatif. Tujuan digunakannya metode tersebut adalah untuk memecahkan masalah yang sedang dianalisis dengan memaparkan objek penelitian berdasarkan data yang ditemukan. Data-data yang ditemukan dalam penelitian ini diperoleh dari teks novel When Hitler Stole Pink Rabbit karya Judith Kerr kemudian diidentifikasi berdasarkan informasi terkait rasisme, dan bagaimana perspektif tokoh-tokoh anak Yahudi tentang rasisme. 
Data primer yang digunakan pada penelitian ini adalah artikel jurnal berjudul "Novel Charlotte Karya David Foenkinos: Sebuah Narasi Tentang Diskriminasi, Rasisme, dan Holocaust." oleh Intan (2017). Lalu sebagai referensi penunjang penulis menggunakan data-data yang diperoleh dari sumber tertulis atau pustaka lainnya seperti buku serta artikel-artikel yang terdapat pada majalah, surat kabar, dan internet. Untuk data-data yang didapat dari buku dan majalah berbahasa asing terlebih dahulu akan dilakukan transliterasi.

Data yang telah dikumpulkan akan dikelompokkan berdasarkan penanda rasisme terhadap tokoh anak Yahudi dalam objek penelitian. Kemudian data tersebut akan diidentifikasi dengan menggunakan konsep rasisme yang dijelaskan oleh Fredrickson. Menurut Fredrickson (2015: 1), rasisme dapat muncul karena preferensi seseorang terhadap latar belakangnya sehingga sering digunakan sebagai cara bebas dan tidak reflektif untuk menggambarkan perasaan negatif dari satu grup etnis, agama atau orang terhadap yang lainnya. Selain itu rasisme adalah reaksi dari sebuah sikap. Kebencian dari sebuah kelompok terhadap kelompok lainnya terkadang diekspresikan dan dilakukan berdasarkan pemikiran tunggal, sepihak dan secara brutal, sehingga melampaui prasangka dan keangkuhan. Penanda yang mengindikasikan rasisme juga akan dikategorikan menjadi rasisme institusional dan individual dengan menggunakan teori Better (2008), yakni terdapat dua jenis rasisme. Tipe pertama adalah institutional racism yakni ketika institusi melakukan operasi rutin berskala besar seperti bisnis dan sistem kerja politik untuk untuk merugikan kelompok minoritas umumnya. Kemudian dari rasisme berbasis institusi tersebut muncul turunannya yakni jenis individual racism (individu atau kelompok kecil) yang mengungkapkan perasaan negatif dengan kata-kata dan/atau tindakan terhadap orang berkulit hitam, atau dapat juga dianalogikan menjadi kelompok minoritas atau yang dianggap liyan, dalam artikel ini adalah orang Yahudi. Oleh karena itu, penanda rasisme yang akan dikaji tidak hanya difokuskan pada rasisme yang dilakukan oleh institusi atau rezim Nazi saja, tetapi juga oleh personal-personal lainnya yang memiliki preferensi dalam melakukan tindakan rasisme.

Data-data yang menunjukkan adanya rasisme kemudian akan dianalisis menggunakan teori naratologi Genette (1980). Kemudian perspektif tokoh anak dalam novel When Hitler Stole Pink Rabbit akan dianalisis menggunakan konsep perspektif atau fokalisasi dan voice atau tutur. Fokalisasi merupakan salah satu konsep dari pokok naratologi yang digagas oleh Genette (1980), yakni mood. Mood digunakan untuk menjelaskan intensitas hal yang dibicarakan, yang juga mengungkapkan berbagai sudut pandang (Genette, 1980: 186). Dengan demikian fokalisasi adalah persoalan mengenai sudut pandang karakter mana yang dipakai oleh narator dalam memandang suatu hal atau isu. Genette pun membedakan fokalisasi dengan tutur atau voice. Jika fokalisasi dipakai untuk menyelidiki sudut pandang yang dipakai dalam penceritaan, maka tutur mempersoalkan siapa yang menjadi narator, atau siapa yang menyuarakannya. Dengan demikian, Genette menyatakan secara sederhana bahwa fokalisasi adalah tentang siapa yang memandang, sedangkan tutur adalah persoalan siapa yang berbicara. Jadi, tokoh yang memandang belum tentu adalah yang menyuarakan pandangan tersebut.

Untuk mendukung hal tersebut, Bal (1999: 142) mengemukakan bahwa fokalisasi merupakan relasi antara pandangan (vision) dan yang dilihat tercapai. Dari pendapat Bal, fokalisasi memerlukan pandangan dari siapa yang melihat kejadian 
dari sebuah peristiwa yang diceritakan. Pendapat Bal tersebut didukung oleh Abbot (2002: 66) yang menyatakan bahwa fokalisasi mengacu pada lensa atau kacamata di mana pembaca melihat tokoh dan kejadian dalam teks naratif.

\section{HASIL DAN PEMBAHASAN}

\section{Sastra Anak dalam Wacana Multikulturalisme dan Rasisme}

Sastra anak menurut Hunt (1999: 3-4) dibuat dengan cara dan pendekatan yang berbeda. Jenis karya ini dibuat khusus untuk anak-anak, dengan segala kebutuhan pengetahuan moral yang perlu mereka dapatkan di usianya. Melalui sastra anak, anak belajar untuk memahami dan memaknai hidup dari sudut pandang mereka.

Anak-anak akan belajar melalui sastra anak dari pengalaman sang tokoh utama cerita, yang juga merupakan seorang anak kecil, dalam menjalani hidup, sebagaimana yang diungkapkan Grenby (2008). Bagaimana tokoh tersebut bersosialisasi dengan orang-orang sekitar, persoalan apa yang ia hadapi, usaha apa yang dilakukannya untuk memecahkan masalah, bagaimana hasil yang dapat diraih dari segala usahanya.

Lukens sebagaimana yang dijelaskan oleh Kurniawan (2009: 22) menyatakan bahwa sastra anak adalah karya yang menawarkan dua hal utama, yakni kesenangan dan pemahaman. Gansel (2010: 12) pun menegaskan perihal pemahaman seperti apa yang ideal diberikan oleh sastra anak kepada anak. Ia mengemukakan bahwa:

Sehr schnell ist bei einer Lektüre der Texte zu erkennen, dass die KJL (Kinder-und Jugendliteratur) eben nicht mehr bevorzugt als Mittel zur moralischen Belehrung funktioniert oder eine Art Erziehungsmittel ist. Natürlich gibt es nach wie vor Texte im Bereich der KJL, die darauf abzielen, den jüngeren Lesern spezifische gesellschaftliche Werte und Normen zu vermitteln, aber keineswegs erschöpft sich die KJL in dieser wertsetzenden Funktion. Auch in der Kinderliteratur hat der sogenannte moralische Zeigefinger zunehmend an Bedeutung verloren.

Terlalu cepat menyimpulkan untuk mengenali satu teks sastra anak dan remaja sebagai sebuah teks yang tidak lebih sebagai pembelajaran moral atau alat pendidikan. Seperti pada masa-masa sebelumnya teks sastra anak dan remaja bertujuan menyampaikan nilai-nilai dan norma kemasyarakatan yang spesifik bagi pembaca anak dan remaja. Tetapi demikian nilai-nilai moral itu sudah kehilangan makna.

Seperti pada masa-masa sebelumnya sastra anak dan remaja menjadi media pembelajaran moral atau alat pendidikan yang bertujuan menyampaikan nila-nilai dan norma kemasyarakatan yang spesifik bagi pembaca. Namun nilai-nilai tersebut agaknya kehilangan makna dan fungsinya, sehingga muncul karya sastra yang tidak hanya berfokus pada hal tersebut, tetapi juga berfokus pada pengalaman anak serta pendidikan karakter melalui sejarah dan wacana-wacana tertentu. Hal tersebut kemudian tergambar pada novel When Hitler Stole Pink Rabbit karya Judith Kerr yang erat dengan salah satu wacana penting, yakni wacana multikulturalisme. 
Wacana multikulturalisme mulai merambah sastra anak pada tahun 1960-an ketika beberapa penulis tergerak untuk menulis sastra anak yang menitikberatkan pada isu representasi dari diferensiasi budaya (Gopalakrishnan, 2011: 8-7). Namun Larrick mengemukakan sebagaimana yang dijelaskan oleh Yokota (1993: 156), bahwa pada tahun-tahun tersebut hanya 6,7\% dari buku anak yang menyuguhkan aspekaspek dari Afrika-Amerika pada ilustrasi maupun teks. Hal tersebut menunjukkan bahwa sastra anak masih bersifat eksklusif pada ras dan etnis tertentu, dan mengabaikan yang lainnya, sehingga ras dan etnis lainnya dianggap sebagai liyan. Selain bersifat eksklusif pada ras dan etnis tertentu, terdapat pula sastra anak yang bertendensi rasis pada kelompok tertentu.

Tren tersebut pun menuai kritikan yang salah satunya dikemukakan oleh Hunt (1999: 20), yakni bahwa buku anak-anak harus mendidik, dan sebagai alat untuk membantu menjamin transisi anak-anak Afrika ke budaya literasi, serta mendukung identitas budaya Afrika. Hal tersebut pun dapat berlaku pada ras dan etnis yang tidak mendapatkan hak-hak tersebut atau dianggap liyan di tempat ia tinggal, seperti orang Yahudi yang tinggal saat Nazi berkuasa. Menurut Prabasmoro dkk (2019: 2676-2677), minimnya karya sastra atau produk film untuk anak yang merepresentasikan anak-anak kulit hitam, akan memiliki efek tertentu baik bagi anak kulit hitam maupun kulit putih, yakni semakin banyaknya cerita orang kulit putih dinarasikan oleh orang kulit putih sendiri, sehingga ketidakseimbangan ini kemudian akan membatasi mimpi, ambisi, dan menimbulkan keraguan pada identitas anak kulit hitam yang melekat pada mereka.

Setelah menuai kritikan, tren buku yang bertemakan inklusivitas pun mulai muncul sebagai counter terhadap rasisme. Buku-buku tersebut mengambil sudut pandang tokoh yang mendapat perlakuan rasis sebagai narasi utamanya. Inklusivitas dalam sastra anak menjadi penting karena menurut Gee dan Heath sebagaimana yang dijelaskan oleh Chaudhri dan Teale (2013: 360), bahwa sastra anak dapat berfungsi sebagai media pembelajaran dan faktor penting dalam pembentukan identitas anak-anak. Khusus pada kasus isu Rasisme yang terjadi pada saat Nazi berkuasa, dokumentasi tentang hal tersebut telah dilakukan oleh anakanak penyintas genosida. Dokumentasi tersebut berupa hasil wawancara atau biografi yang dihimpun salah satunya pada laman "Bagso" oleh Guido, Lenz, dan Jonas (2012). Namun hasil dokumentasi tersebut tidak lazim disuguhkan kepada anak-anak karena dianggap belum sesuai dengan perkembangan intelektual mereka. Dengan demikian, sastra anak yang mengemas dokumentasi tersebut mulai bermunculan agar isu rasisme pun dapat disuguhkan kepada anak-anak.

\section{Rasisme dan Perspektif Tokoh Anak}

Dalam novel When Hitler Stole Pink Rabbit, tokoh Anna dan Max merupakan kakak beradik Yahudi yang lahir dan besar di Jerman. Mereka hidup dengan nyaman dan aman di sana karena Ayah mereka merupakan seorang penulis terpandang yang tulisannya telah berkali-kali dicetak dan kerap menjadi acuan di Jerman. Namun ketenaran Ayahnya kemudian menjadi bumerang bagi mereka ketika Hitler memimpin Jerman. Kala itu, ayah Anna merupakan tokoh Yahudi yang kerap mengkritik Nazi, sehingga ia menjadi buronan negara.

Pada kepemimpinan Nazi, Anna dan Max mengalami titik balik terbesar dalam hidup mereka sebagai anak-anak dari keluarga terpandang dan kaya, menjadi anak- 
anak buronan yang jatuh miskin dan terpuruk. Anna dan Max dihadirkan sebagai tokoh anak yang sadar terhadap rasisme dan diskriminasi yang mereka terima. Meskipun sadar akan keliyanan yang melekat, mereka tetap ingin meresistensinya, meskipun tinggal di lingkungan yang meliyankan mereka. Berikut kutipan yang menunjukkan bahwa Anna sadar atas rasisme yang ia dapatkan:

'It's quite simple,' said Mama. 'Papa thinks Hitler and the Nazis might win the elections. If that happened he would not want to live in Germany while they were in power, and nor would any of us.' 'Because we're Jews?' asked Anna. (Kerr, 1971: 19)

"Sederhana saja," kata Mama. 'Papa berpikir Hitler dan Nazi mungkin saja akan memenangkan pemilu. Jika itu terjadi, dia tidak akan mau tinggal di Jerman saat mereka berkuasa, dan begitu pula dengan kita.' "Karena kita orang Yahudi?" tanya Anna.

Situasi dalam kutipan tersebut merupakan fokalisasi tentang Yahudi yang hadir dari pandangan Anna. Pandangan tersebut ia tuturkan berdasarkan informasi yang diberikan mama kepadanya tentang Hitler yang akan memimpin Jerman sebagai sebab perginya mereka dari Jerman. Dalam hubungan sebab akibat tersebut Anna memandang adanya premis penting yang menjalankan hubungan tersebut, yakni identitasnya sebagai Yahudi. Ia merespon pernyataan sang mama dengan datar dan tegar. Ia pun menyadari bahwa menjadi seorang Yahudi menjadikannya dan keluarganya tidak aman selama berada dalam daerah kekuasaan orang atau pemerintah yang rasis terhadap mereka. Dalam tataran ini, dapat diasumsikan bahwa Anna memandang bahwa rasisme adalah bentuk kebencian orang lain atas identitas yang lekat pada dirinya, yakni Yahudi. Kesadaran akan rasisme yang dilakukan oleh Nazi sebagai institusi ditunjukkan pula oleh Max, kakak Anna yang terlihat dari kutipan 'But why should they?' asked Max. 'If the Nazis don't like us, surely they'd be glad to get rid of us.' (Kerr, 1971: 29), yang artinya "'Tapi kenapa harus mereka?" tanya Max. "Jika Nazi tidak menyukai kita, pasti mereka akan senang menyingkirkan kita"".

Tepat pada tahun 1933 setelah Hitler yang memimpin Nazi berkuasa di Jerman, ia mendeklarasikan bahwa orang Yahudi sebagai "un-German" atau bukan orang Jerman dan menggaungkan program kerja "judenfrei" atau "Jerman bebas dari orang Yahudi" dengan membasmi tempat tinggal, hak-hak sipil, mata pencaharian, dsb (Deem, 2012: 6). Bentuk kebijakannya tersebut terimplementasi dengan menjadikan orang-orang Yahudi sebagai subjek persekusi dan mengucilkan mereka. Tindakan Nazi tersebut dijelaskan oleh Better (2008: 30) sebagai jenis rasisme institusi, yakni kebijakan dan praktik yang memiliki konsekuensi yang tidak sama untuk minoritas dan cenderung diskriminatif dengan cara berprasangka atau bertindak diskriminasi secara terang-terangan.

Hubungan antara data sejarah dan novel semi-autobiografi ini pun memiliki benang merah, sehingga kebijakan Nazi yang tertulis pada sumber sejarah tersebut juga tergambar pada novel When Hitler Stole Pink Rabbit. Dampak besar yang terjadi 
pada keluarga Anna, terutama ayahnya saat itu yakni kebijakan dilarangnya tulisan tentang Yahudi dan karyanya, serta boikot terhadapnya. Setelah terjadi persekusi dan larangan terhadap orang Yahudi dan karya mereka, ayah Anna memutuskan untuk lari dari Jerman. Dari pelarian tersebut Anna dan Max merasa Nazi mengambil dan merengut semua milik mereka. Hal tersebut dapat digambarkan pada kutipan berikut:

The last days Anna and Max spent at school were very strange. As they still were not allowed to tell anyone that they were leaving they kept forgetting about it themselves during school hours. Anna was delighted when she was given a part in the school play and only remembered afterwards that she would never actually appear in it. Max accepted an invitation to a birthday party which he would never be able to attend. (Kerr, 1971: 30)

Hari-hari terakhir yang Anna dan Max habiskan di sekolah sangatlah aneh. Karena mereka masih tidak diizinkan memberi tahu siapa pun bahwa mereka akan pergi, mereka terus melupakannya sendiri selama jam sekolah. Anna sangat senang ketika dia diberi peran dalam drama sekolah dan hanya ingat setelah itu bahwa dia tidak akan pernah benar-benar muncul di drama tersebut. Max pun menerima undangan ke pesta ulang tahun yang tidak akan pernah bisa dia hadiri.

Dalam kutipan tersebut narator memfokalisasikan Anna dan Max tentang kepergian mereka dari Jerman karena rasisme yang dimunculkan oleh Nazi yang menunjukkan bahwa keadaan tersebut membuat mereka tidak dapat lagi bersekolah dengan normal, bermain setelah sekolah dan menghadiri pesta ulang tahun. Mereka pun merasa direpresi ketika dipaksa memilih hanya satu dari ratusan mainan yang mereka punya di rumah ketika harus pergi. Hal tersebut tergambar dari kutipan berikut:

Deciding which toys to take was the hardest part. They naturally wanted to take the games compendium but it was too big. In the end there was only room for some books and one of Anna's stuffed toys. Should she choose Pink Rabbit which had been her companion ever since she could remember, or a newly acquired woolly dog? (Kerr, 1971: 30-31)

Memutuskan mainan mana yang akan diambil adalah bagian tersulit. Mereka secara alami ingin membawa koleksi permainan mereka tetapi itu terlalu besar. Pada akhirnya hanya ada ruang untuk beberapa buku dan salah satu boneka Anna. Haruskah dia memilih Kelinci Merah Muda yang telah menjadi temannya sejak dia bisa mengingatnya, atau anjing berbulu yang baru ia peroleh?

Fokalisasi Anna yang dituturkan oleh narator tentang mainan yang tidak dapat ia bawa tersebut dapat diasumsikan sebagai simbol perampasan hak miliknya oleh Hitler sebagai penguasa yang rasis. Namun ia tetap ingin meresistensinya dan menegosiasikan keadaan inferiornya dengan setidaknya dapat membawa satu 
mainan yang paling disukai melalui berbagai pertimbangan yang lama dan matang karena menurutnya hal tersebut adalah hal tersulit yang harus ia putuskan.

Perampasan Hitler terhadap kepemilikan Anna dan Max yang telah disebutkan sebelumnya, yakni sekolah, pertemanan, hingga mainan menyadarkan Anna bahwa rasisme yang dilakukan oleh Hitler telah merampas psikis dan masa kecilnya. Hal tersebut terlihat ketika Anna dan keluarganya berada di dalam kereta menuju Swiss, negara pertama tempat mereka mengungsi. Kala itu ia terus berkata di dalam hati, yakni "difficult childhood ... difficult childhood ... difficult childhood ..." (Kerr, 1971: 38) yang berarti "masa kecil yang sulit ... masa kecil yang sulit ... masa kecil yang sulit ...". Fokalisasi Anna terhadap apa yang menimpanya tersebut dituturkan oleh narator.

Kesadaran Anna dan Max tentang perenggutan segala hal yang dimiliki mereka oleh Nazi dijabarkan ketika mereka sudah sampai di Swiss. Di sana mereka merasa asing, hampa, dan gelisah.

... she said, 'Max, this ... confiscation of property, whatever it's called - did the Nazis take everything - even our things?' Max nodded. Anna tried to imagine it. The piano was gone ... the dining-room curtains with the flowers ... her bed ... all her toys which included her stuffed Pink Rabbit. For a moment she felt terribly sad about Pink Rabbit. (Kerr, 1971: 57)

... dia (Anna) berkata, 'Max, ini ... penyitaan properti, apa pun namanya apakah Nazi mengambil semuanya - bahkan barang-barang kita?' Max mengangguk. Anna mencoba membayangkannya. Pianonya hilang ... tirai ruang makan dengan bunga-bunga ... tempat tidurnya ... semua mainannya termasuk boneka Kelinci Merah Muda miliknya. Sesaat dia merasa sangat sedih tentang Kelinci Merah Muda.

Fokalisasi Anna dan Max atas kesadaran bahwa Nazi merampas semua milik mereka didukung oleh tutur dari narator yang merinci barang-barang tersebut sekaligus menggambarkan suasana hati Anna ketika mengingat salah satu mainan miliknya. Perincian barang-barang tersebut pun dapat menggambarkan masifnya represi Nazi terhadapnya dan keluarga, mulai dari hal-hal besar yang digambarkan secara harfiah oleh Anna, yakni piano, sampai pada hal kecil namun juga penting baginya yang ia simbolkan sebagai boneka kelincinya. Represi yang dilakukan oleh Nazi tidak hanya pada perenggutan hak, tetapi juga pada statusnya sebagai orang Jerman.

Tibanya Anna dan keluarganya di Swiss secara tidak langsung mendeklarasikan bahwa mereka telah menjadi pengungsi yang lari dari Nazi dan Jerman. Berdasarkan pengalaman yang ia dapatkan, narator memfokalisasikan Anna tentang pengungsi, bahwa menjadi pengungsi dari Nazi adalah hal yang menyedihkan karena ia tak dapat merayakan ulang tahun ke-sepuluh dan seterusnya seperti dulu. Menjadi pengungsi menurutnya tinggal secara terasingkan di negara asing sepanjang hidup dan tidak memiliki apapun (Kerr, 1971: 81-83). Namun Anna tidak ingin larut dalam kesedihan tersebut dan ia menolak membiarkan Nazi merengut semua darinya. Ia pun meresitensinya dengan menganggap bahwa 
menjadi pengungsi adalah hal yang bagus kerena ia dapat menjadi seorang petualang yang dapat bepergian ke berbagai tempat yang aman. Masa kecilnya yang sulit pun dapat ia analogikan seperti kisah dalam buku Gunther yang kelak akan membuatnya menjadi kuat dan terkenal (Kerr, 1971: 83).

Setelah Anna dan keluarganya tidak lagi berada di Jerman, hal tersebut tidak serta-merta membuat mereka "bebas" dari Nazi. Nazi menyebarkan propaganda, fitnah dan kebohongan tentang orang Yahudi di Jerman maupun di negara-negara Eropa lainnya seperti yang dijelaskan oleh ayah dalam kutipan "There are Jews scattered all over the world,' he said, 'and the Nazis are telling terrible lies about them.... 'For instance, the Nazis say that Jews are dishonest.'" (Kerr, 1971: 105) yang artinya "'Ada banyak orang Yahudi tersebar di seluruh dunia,' kata dia (ayah), 'dan Nazi sedang menyebarkan kebohongan tentang mereka... 'Misalnya, Nazi mengatakan bahwa orang Yahudi tidak jujur.'". Anna pada awalnya memandang bahwa anggapan Nazi tersebut adalah akibat dari tindakannya di masa lalu. Ia mengakui bahwa tindakan tidak jujur pernah ia lakukan ketika membeli pensil di Berlin dengan uang yang kurang

(Anna at once thought guiltily of the last time she had bought a pencil in Berlin. The man in the paper shop had not charged her quite enough and Anna had not pointed out the mistake. How the Nazis had got to hear of this?) (Kerr, 1971: 106).

(Anna langsung merasa bersalah saat terakhir dia membeli pensil di Berlin. Pria di toko kertas itu tidak menagihnya dengan cukup dan Anna tidak menunjukkan kesalahannya. Bagaimana Nazi mendengar ini?)

Fokalisasi Anna tersebut dituturkan oleh narator sebagai bentuk penerimaan terhadap diskriminasi yang dialaminya dan pengakuan bahwa ia memang tidak suci dan sempurna. Namun setelah menerima semua itu, Anna bertekad meresistensinya dengan menjadi anak yang lebih baik dan menjadi representatif orang Yahudi yang baik. Hal tersebut dapat dilihat melalui kutipan:

It was funny, thought Anna. Normally she hated to be told that she must be extra good, but this time she did not really mind. She had not realised before that being a Jew was so important. Secretly she resolved really to wash her neck with soap each day while Mama was away so that at least the Nazis would not be able to say that Jews had dirty necks. (Kerr, 1971: 106)

Itu lucu, pikir Anna. Biasanya dia tidak suka diberitahu bahwa dia harus ekstra baik, tapi kali ini dia tidak terlalu keberatan. Dia tidak pernah menyadari sebelumnya bahwa menjadi seorang Yahudi itu sangat penting, Diam-diam dia memutuskan untuk benar-benar mencuci lehernya dengan sabun setiap hari selama Mama pergi sehingga setidaknya Nazi tidak akan bisa mengatakan bahwa orang Yahudi memiliki leher yang kotor.

Pandangan Anna tentang Nazi pun tidak terlepas dari pengaruh orangorang dewasa di sekitarnya. Hal ini digambarkan oleh percapakan antara Anna dan Max dengan orang tua serta paman mereka yang sering berdiskusi tentang Hitler, 
Nazi, dan Jerman. Salah satu topik yang dibahas adalah pembakaran massal bukubuku yang ditulis oleh orang Yahudi. Ayah Anna yang merupakan salah satu penulis tersohor di Jerman pun merasakan dampaknya. Hal tersebut tergambar pada kutipan berikut:

'The Nazis certainly are very stupid,' said Onkel Julius. 'How could you possibly be an enemy of Germany? You know of course that they burned all your books.' 'What books?' asked Anna. 'I thought the Nazis had just taken all our things - I didn't know they'd burned them.' 'These were not the books your father owned,' said Onkel Julius. 'They were the books he has written. The Nazis lit big bonfires all over the country and threw on all the copies they could find and burned them.' (Kerr, 1971: 64)

"Nazi memang sangat bodoh," kata Paman Julius (pada ayah). Bagaimana mungkin kamu bisa menjadi musuh Jerman? Kamu tentu tahu bahwa mereka membakar semua bukumu." “Buku apa?" tanya Anna. “Saya pikir Nazi hanya mengambil semua barang kami - saya tidak tahu bahwa mereka juga membakarnya." Ini bukan buku yang ayahmu miliki," kata Paman Julius. "Itu adalah buku-buku yang dia tulis. Nazi menyalakan api unggun besar di seluruh negeri dan melemparkan semua salinan yang bisa mereka temukan dan membakarnya."

Pandangan tersebut pun menambah khazanah fokalisasi Anna tenang Nazi dan semua diskriminasi yang ia dan keluarganya terima. Ia pun menyadari bahwa diskriminasi ini tidak hanya merepresentasikan kebencian Hitler terhadap latar belakang etnis keluarganya tetapi juga terhadap ideologi mereka. Penetrasi pandangan orang dewasa ke pola pikir Anna tersebut pun disadari oleh Anna yang dijelaskan dan dituturkan secara tersirat oleh narator pada kutipan "All grown-up conversation were like this nowadays, thought Anna, ..." (Kerr, 1971: 66), yang artinya "Semua percakapan orang dewasa seperti ini sekarang, pikir Anna..."

Seperti yang telah dikemukakan oleh Better (2008: 30), bahwa jenis rasisme institusi akan berdampak munculnya jenis rasisme individu, yakni ketika individu (atau kelompok kecil individu) memiliki sikap curiga dan/atau terlibat dalam perilaku diskriminatif dan sejenisnya. Manifestasi rasisme individu adalah stereotip individu atas dasar dugaan perbedaan ras, menghina nama dan referensi, perlakuan diskriminatif selama kontak interpersonal, ancaman, dan tindak kekerasan terhadap anggota kelompok minoritas yang diduga menjadi ras inferior.

Penjelasan tersebut berbanding lurus dengan apa yang dialami Anna dan keluarganya. Mereka tidak hanya memperoleh tindak rasis dari Nazi, tetapi juga dari individu atau kelompok individu yang memiliki prasangka, stereotip, dan preferensi terhadap orang Yahudi. Rasisme individual pertama yang dialami oleh Anna dan Max adalah ketika mereka tidak lagi bisa bermain dengan anak-anak pemilik hotel tempat mereka tinggal sementara di Swiss karena salah satu pelanggannya adalah pendukung Nazi dan tidak memperbolehkan anak mereka dan anak-anak pemilik hotel bermain dengan Anna dan Max karena mereka adalah orang Yahudi. Hal tersebut ditunjukkan dengan kutipan “'They're Nazis,' she said at last. 'They've forbidden 
their children to play with ours because our children are Jewish!'" (Kerr, 1971: 89) yang artinya "'Mereka adalah Nazi' dia (mama) berkata. "Mereka melarang anak-anak mereka bermain dengan anak-anak kita karena kita Yahudi!'”. Anna dan Max tidak digambarkan memandang hal tersebut negatif atau sedih baik dari tutur mereka maupun dari tutur narator. Mereka awalnya memandang dengan heran, namun mereka tetap melanjutkan bermain berdua saja. Anna pun dengan yakin berkata "'But it seems such a pity,' said Anna. 'I'm sure that boy really liked us.'" (Kerr, 1971: 92), yang artinya "'Tapi sayang sekali,' kata Anna. 'Aku yakin anak itu (pro Nazi) sangat menyukai kita." Anna tidak memandang diskriminasi tersebut sebagai sesuatu yang harus dirisaukan dan bahkan ia tidak membenci anak Jerman tersebut. Ia pun merasa kasihan terhadap anak tersebut dan ingin menariknya pergi dari keluarga yang rasis dan menanamkan rasa benci kepada mereka.

Setelah Ayah memutuskan untuk pindah ke Perancis, Anna dan keluarganya tetap mendapat diskriminasi. Berbeda dengan Anna yang dapat menahan emosinya, Max agaknya tidak dapat menahan diskriminasi yang ia rasakan di sekolah barunya di Perancis. Hal tersebut dapat dilihat dari kutipan berikut:

He was silent and morose for the rest of the evening. Only after supper he suddenly said to Mama, 'I've got to have a proper French briefcase.' He kicked the German satchel which he normally carried strapped to his back. 'If I go round carrying this I even look different from everyone else.' (Kerr, 1971: 144)

Dia (Max) diam dan murung sepanjang sisa malam itu. Baru setelah makan malam dia tiba-tiba berkata pada Mama, Aku harus punya tas Perancis yang layak." Dia menendang tas Jerman yang biasanya dia bawa dengan terikat di punggungnya. "Jika saya pergi berkeliling membawa ini, saya bahkan akan terlihat berbeda dari orang lain."

Pada kutipan tersebut Max dan pengarang sebagai narator memfokalisasikan Max tentang diskriminasi yang ia peroleh. Max merasa dibedakan dan dijauhi oleh temantemannya di sekolah di Paris karena tas yang ia punya adalah tas yang biasanya dipakai oleh anak Jerman. Ia pun merasa frustasi sehingga membanting tasnya dan marah kepada mama. Ia pun menuntut mama agar dibelikan tas baru yang sama seperti tas teman-temannya. Ia benci menjadi anak yang selalu berbeda dari anakanak lainnya. Max merasa rasisme itu kejam karena menilai manusia hanya dari apa yang ia tampilkan. Apa yang ia pakai dapat menentukan identitas dirinya dan siapa dirinya oleh teman-temannya, sehingga menurutnya tas sekolah merupakan indikator dirinya dibedakan dan didiskriminasi oleh teman-teman barunya di Paris.

\section{PENUTUP}

Terdapat dua jenis rasisme yang ditampilkan dalam novel When Hitler Stole Pink Rabbit karya Judith Kerr, yakni jenis rasisme institusi yang ditunjukkan oleh Nazi, serta jenis rasisme individu yang ditunjukkan oleh anak dan orang tua Jerman yang pro terhadap Nazi, dan teman-teman sekolah Max. Perspektif atau fokalisasi Anna dan Max terhadap rasisme dituturkan oleh Anna, Max, dan narator. Perspektif tersebut menunjukkan kesadaran Anna dan Max bahwa rasisme adalah bentuk 
kebencian atas identitas yang melekat pada diri mereka, yakni Yahudi. Selain identitas yang melekat, rasisme juga bentuk kebencian atas perbedaan fisik serta ideologi. Bagi Anna dan Max, rasisme adalah bentuk perenggutan segala yang mereka punya, yakni harta benda dan masa kecil yang indah. Mereka pun memandang bahwa rasisme adalah hal yang menakutkan dan menyedihkan. Namun dibalik kesadaran atas tindakan rasisme tersebut, Anna dan Max difokalisasikan dapat meresistensinya. Mereka memilih berdamai dengan diri mereka sendiri dan memandang segala sesuatu dari sisi positif, serta berusaha untuk tidak membenci pihak-pihak yang mendiskriminasi mereka. Bagi Anna, menjadi orang Yahudi yang lebih baik adalah resistensi terbaik karena setidaknya ia dapat mematahkan prasangka yang diyakini oleh Nazi dan orang-orang yang tidak menyukai orang Yahudi.

\section{DAFTAR PUSTAKA}

Abbot, H. P. (2002). The Cambridge Introduction to Narrative. Cambridge: The PressSyndicate of The University of Cambridge.

Akmen, T. (2019). Jewish children's book author Judith Kerr dies at 95. Obituary. diakses dari https://www.timesofisrael.com/jewish-childrens-bookauthor-judith-kerr-dies-at-95/ tanggal 19 Desember 2019

Bal, M. (1999). Narratology Introduction to The Theory of Narrative second edition. Toronto: University of Toronto Press.

Banks, P. A. (2020). Race, Ethnicity, and Consumption: A Sociological View. New York: Taylor \& Francis.

Barkan, E. (1992). The Retreat of Scientific Racism: Changing Concepts of Race in Britain and the United States Between the World Wars. Cambridge: Cambridge University Press.

Better, S. (2008). Institutional Racism: A Primer on Theory and Strategies for Social Change. Maryland: Rowman \& Littlefield Publishers.

Bhabha, H. K. (2015). Debating Cultural Hybridity Multicultural Identities and The Politics of Anti-Racism (P. Werbner \& T. Modood Eds.). London: Zed Books Ltd.

Blumenbach, J. F. (2018). Johann Friedrich Blumenbach: Race and Natural History, 17501850 (N. Rupke \& G. Lauer Eds.). New York: Taylor \& Francis.

Chaudhri, A., \& Teale, W. H. (2013). "Stories of Multiracial Experiences in Literature for Children, Ages 9-14." dalam Jurnal Children's Literature in Education, Vol. 44, hlm. 359-376. doi: 10.1007/s10583-013-9196-5

Collins, W. (2018). Collins English Dictionary (C. Dictionaries Ed. 13th ed.). New York: HarperCollins Publishers Limited.

Deem, J. M. (2012). Kristallnacht: The Nazi Terror That Began the Holocaust. Berkeley: Enslow Publishing, LLC.

Elias, S., \& Feagin, J. R. (2016). Racial Theories in Social Science: A Systemic Racism Critique. New York London: Routledge. 
Fredrickson, G. M., \& Camarillo, A. (2015). Racism: A Short History. New Jersey: Princeton University Press.

Gansel, C. (2010). Moderne Kinder- und Jugendliteratur. Berlin: Cornelsen.

Genette, G. (1980). Narrative Discourse: An Essay in Method (J. E. Lewin., Trans.). New York: Cornell University Press.

Gopalakrishnan, A. (2011). Multicultural Children's Literature: A Critical Issues Approach. Thousand Oaks

Thousand Oaks, California: SAGE Publications, Inc.

Grenby, M. O. (2008). Children's Literature. Edinburgh: Edinburgh University Press.

Guido Klumpp, G., Lenz, U., \& Jonas, I. (2012). Kriegskinder. Bagso-Nachrichten, 4, hlm. 3.

Hunt, P. (1999). Understanding Children's Literature. London: Routledge.

Intan, T. (2017). "Novel Charlotte Karya David Foenkinos : Sebuah Narasi Tentang Diskriminasi, Rasisme, dan Holocaust." dalam Jurnal Poetika, Vol. $V$ (Desember), hlm. 97-108. doi: 10.22146/poetika.28979

Kerr, J. (1971). When Hitler Stole Pink Rabbit. London: William Collins and Sons and Co. Ltd.

López, I. F. H., \& Delgado, R. (1999). Critical Race Theory: The Cutting Edge. Philadephia: Temple University Press.

Manuaba, I. B. P. (2019). Wacana Bahasa dan Sastra. Surabaya: Airlangga University Press.

Muqil, I., \& Kurniawati, W. (2015). "Rasisme dalam Novel Hanas Koffer Karya Levine." dalam Jurnal Mahasiswa UNESA, Vol. IV, hlm. 1-6

Prabasmoro, T., Budhyono, R., \& Muhtadin, T. (2019). "Black Panther: Identity, Afrofuturism, and Representation of Superheroes." dalam Jurnal Pertanika, Vol. 27, hlm. 2672-2685.

Sontheimer, M. (Producer). (2005, Juny). Der Zweite Weltkrieg. [Spiegel Online] diakses dari https://m.spiegel.de/spiegel.de/spiegel/print/d39257689.html tanggal 1 Juni 2019

Yokota, J. (1993). "Issues in Selecting Multicultural Children's Literature." dalam Jurnal Language Arts, Vol. 70(3), hlm. 156-167. 